\title{
Exploring Relationships Between Passion and Attitudes Toward Performance Enhancing Drugs in Canadian Collegiate Sport Contexts
}

\author{
Austin W. Wilson \\ University of Waterloo \\ Luke R. Potwarka \\ University of Waterloo
}

\begin{abstract}
The purpose of this study was to explore relationships between passion and attitudes toward performance enhancing drugs (PEDs). Participants were 587 male and female varsity and coed intramural athletes from four Southern Ontario universities. Athletes completed the passion scale (Vallerand et al., 2003) and the performance enhancement attitudes scale (Petróczi, 2006). Full sample regression analyze revealed that higher scores on obsessive passion items were associated with more permissive attitudes toward PEDs $(B=, 26, p<.001)$, while higher scores on harmonious passion items were associated with less permissive attitudes toward PEDs $(B=-.29, p<.001)$. Moreover, obsessive passion emerged as a significant positive predictor of attitudes toward PEDs in all study contexts (i.e., coed recreational athletes, male/female varsity athletes). Implications for sport administrators, study limitations, and possible avenues for future research are discussed.
\end{abstract}

Keywords: passion, attitudes toward performance enhancing drugs, collegiate and recreational sport

The prevalence of the exposure to, interest in, and availability of performance enhancing drugs (PEDs) continues to be a concern in North American collegiate sporting environments (Yusko, Buckman, White, \& Pandina, 2008). According to the National Center for Drug Free Sport (2013) PEDs, are considered any substance that is taken to perform better athletically. Specifically, we use the terms "doping", "performance enhancing drugs", and "performance enhancements" interchangeably throughout the paper to refer to any substance or method that is prohibited by the World Anti-Doping Agency (WADA). Substances and methods prohibited (i.e., illegal) by WADA include, but are not limited to anabolic androgenic steroids,

The authors are with the Dept. of Recreation and Leisure Studies, University of Waterloo, Waterloo, Ontario, Canada. Address author correspondence to Austin Wilson at aw3wilso@uwaterloo.ca. 
manipulation of blood and blood components, gene doping, and recreational drugs such as stimulants, narcotics, and cannabinoids (WADA, 2014). For the purpose of this paper, PEDs refer to any substances or methods that appear on a list of banned substances by a sport governing body (e.g., WADA, NCAA).

The National Collegiate Athletic Association (NCAA) indicates that although anabolic steroid use by college athletes may be declining, the list of NCAA banned substances continues to expand and now includes more anabolic agents, peptide hormones, and analogs, and releasing factors (NCAA, 2008). Athletes are exposed to ephedrine and amphetamines to boost metabolism and endurance, while nutritional supplements and weight loss products can be used to control weight and improve health, and prescription pain killers are used to mask injury with or without valid prescriptions (Tricker, 2000).

Indeed, PEDs remain a significant problem in many college settings as some student athletes continue to view these ergogenic compounds as beneficial, even though the performance benefits and health risks are still poorly understood (Buckman, Farris, \& Yusko, 2013; Calfee \& Fadale, 2006). Moreover, it is well documented that groups other than elite varsity athletes, (e.g., competitive recreational participants) are becoming exposed to doping agents, especially steroids (Baron, Martin, \& Magd, 2007; Irving, Wall, Neumark-Sztainer, \& Story 2002; Kindlundh, Isacson, Berglund, Nyberg, 1999; McDuff \& Baron, 2005; Petróczi, 2007).

Thus, a better understanding of the nature and forces that shape attitudes toward PEDs seems warranted. Specifically, we believe delving deeper into the psychological processes and mechanisms by which athletes come to perceive PEDs as being "permissible" or "acceptable" is worthy of attention by researchers. To date, few studies have explored factors that might shape collegiate athletes' attitudes toward PEDs. Although we adopt the position that more permissible attitudes toward PEDs are negative for society, we acknowledge that not all people share our perspective.

Our paper posits that one factor that might shape collegiate athletes' attitudes toward PEDs might be linked to emerging psychological conceptualizations of passion. Passion has been defined as a strong liking for an object, concept, or activity (Vallerand, 2010). Passion can bring out the best and the worst in people, and as much as the construct of passion is used in everyday life, little research exists on its role as a psychological mechanism that might help understand how athletes perceive PEDs in the world of sport (Vallerand, 2010). It has been suggested that passion for one's sport may influence people's stance on issues such as PEDs, especially if such love is entrenched in a sense of identity that is contingent on doing well in their particular sport (Donahue, Rip, \& Vallerand, 2009).

People often associate passion with positive words such as "love," "loyalty," "determination," "dedication", and "perseverance". However, recent research has suggested that passion can become "obsessive," in nature, to the extent that participation in certain sporting activities becomes more of a controlling, dominating, and dependent force within athletes' lives than a more balanced (i.e., harmonious) aspects of their life (Hagger \& Chatzisarantis, 2005; Vallerand, 2010). We contend that that competitive sport can become a controlling and domination force in peoples' lives. To this end, our study attempts to demonstrate predictive associations between two dimensions of passion (i.e., obsessive and harmonious) and attitudes toward PEDs. To our knowledge, researchers have not attempted to link these two constructs. 
Our study is exploratory in nature. We do not propose passion as the panacea for explaining attitudes toward PEDs. Rather, we hope future research builds on our study by including passion in conceptual and empirical models attempting to explain attitudes and behaviors associated with PEDs.

Therefore, the purpose of the current study is to explore relationships between passion for competitive sport activities and attitudes toward PEDs. Specifically our investigation seeks to explore the following four research questions (RQs):

1. Does passion predict attitude toward PEDs in competitive collegiate sporting environments (i.e., both varsity and coed recreational sport contexts)?

2. Does passion predict attitude toward PEDs in coed recreational collegiate sporting environments?

3. Does passion predict attitude toward PEDs in varsity collegiate sporting environments?

4. Does passion predict attitude toward PEDs in male and female varsity sporting environments?

\section{Literature Review}

Vallerand (2010) indicates that the concept of passion has had many definitions over the years; however he suggests passion reflects a strong liking for an activity, object or concept.

This definition is able to circumscribe what passion is and what being passionate means. For instance, passion is usually oriented toward an object or activity, meaning that someone is passionate about ice hockey, collecting stamps, or being attracted to a loved one. Being passionate entails being emotionally charged, or at the least, being affectively inclined toward the object or activity, indicating that passion and emotion are related (Vallerand, 2010). Affect toward the object of one's passion implies that the person values the object, if not; no affect or liking would be experienced. Moreover, as there is an intimate person-object link that is rooted in identity, passion should lead people to pursue the object or activity with vigor on a long-term basis, meaning that when people are passionate for something they typically engage regularly for several years and sometimes a lifetime (Vallerand, 2010). The following discussion reviews literature related to the construct of passion, passions' relationship to sport-related behaviors, and concludes with a discussion of attitude toward PEDs in sport.

\section{A Dualistic Model of Passion}

Vallerand and colleagues (Vallerand, 2008; Vallerand \& Houlfort, 2003; Vallerand et al., 2003) have developed a dualistic model of passion (DMP) that addresses the dualism inherent in the conceptualization of passion. The model is grounded in 1) passion is directional toward an object/activity, and 2) passion is linked to identity (Vallerand, 2012). The DMP is in line with Self-Determination Theory (Deci \& Ryan, 2000; SDT), proposing that people engage in various activities throughout life in hope of satisfying the basic psychological needs of autonomy (a desire to feel a sense of personal initiative), competence (a desire to interact effectively with 
the environment), and relatedness (a desire to feel connected to significant others). The DMP defines passion as a strong inclination toward a self-defining activity that one's likes or loves, finds important, and in which one invests time and energy. In addition, these activities can come to be so self-defining that they represent central features of one's identity (Vallerand, 2010). Moreover, passion means more than experiencing love for an activity, it also entails valuing the activity to a high degree, devoting ample time to it, and making it one of the central aspects of one's identity and life (Vallerand, 2010). Essentially, the DMP posits that different internalization processes are associated with the development of two types of passion toward an activity, specifically obsessive and harmonious passion (Vallerand et al., 2003).

Obsessive Passion. Obsessive passion results from a controlled internalization of an activity into one's identity. This controlled internalization results from an "intra and/or interpersonal pressure typically because certain contingencies are attached to the activity such as feelings of social acceptance and self-esteem or because the sense of excitement derived from the activity engagement is uncontrollable" (Vallerand 2010, p, 102). With obsessive passion, individuals partially or fully internalize the values, regulations, and norms associated with an activity. Such internalization can produce feelings of having a lack of control over engaging in an activity (Vallerand, 2010).

In other words, people with an obsessive passion for an activity can find themselves in the position of experiencing uncontrollable urges to participate (Vallerand, 2010). In these instances, people risk experiencing conflicts and other negative affective, cognitive, and behavioral consequences during and after the activity engagement (Vallerand, 2010). When people are "obsessively passionate" they may demonstrate rigid persistence or dependence on an activity (Vallerand, 2010). With such a rigid persistence, people can experience conflict with other aspects of their life (e.g., family, school, work, etc.) when engaging in the activity, as well as frustration and rumination about the activity when prevented from participating (Vallerand, 2010). Researchers have suggested this to be the case because internally controlling, rather than integrative, self-processes (Hodgins \& Knee, 2002), tend to be at play with obsessive passion. Internally controlling processes may lead the person to engage in the activity with a fragile and contingent sense of self-esteem (e.g., Crocker, 2002; Kernis, 2003), and eventually become defensive rather than open to new experiences and information. These contingencies can lead the individual to become dependent on the passionate activity and to suffer emotionally in the face of failure (Vallerand 2010).

Dependence and rigid persistence that obsessive passion creates can have some benefits in the lives of athletes (e.g., sustained involvement and improved performance in the activity) (Vallerand, 2010). However, it may also come at a cost. Because performance may be tied to self-esteem and sense of identity, the more "obsessively passionate" athlete may be more likely to do whatever it take to win, and maintain optimal performance.

Harmonious Passion. Harmonious passion results from an autonomous internalization process, which "occurs when individuals have freely accepted the activity as important for them without any contingencies attached to it" (Vallerand, 2010, p, 103). Deci and Ryan (2000) and Ryan and Deci (2003) indicate that this type of internalization emanates from the intrinsic and integrative tendencies of the self 
and produce a motivational force to engage in the activity willingly and engenders a sense of volition and personal endorsement about pursing the activity. When harmonious passion is the focus, individuals do not experience uncontrollable urges to engage in the passionate activity, but rather freely choose to do so (Vallerand, 2010). Engagement in this type of passion is conducive to positive experiences and people should be able to fully focus on the task and experience positive feelings both during the activity and after and therefore, should be no conflict to the person's passionate activity and his or her other life activities (Vallerand, 2010). Furthermore, Vallerand indicates that when prevented from engaging in the passionate activity, people with a harmonious passion should be able to adapt well to the situation and focus their attention on other life tasks. In addition, with harmonious passion the person is in control of the activity and can decide when to and when to not engage in the activity (Vallerand, 2010). Therefore, the more "harmoniously passionate" athlete may be less likely to turn to banned or illegal substances to maintain participation and performance.

\section{Passion and Sport-Related Behavioral Outcomes}

We do not explore passion as a predictor of PED-related behavior (i.e., actual use or intention to use PEDs). However, previous sport research has examined the DMP in relation to performance-based behavioral outcomes and acts of aggression.

Performance. Research on expert performance reveals that high-level performers, including athletes spend considerable time on deliberate practice to reach excellence in their chosen field (Ericsson \& Charness, 1994; Starkes, Deakin, Allard, Hodges, \& Hayes, 1996). Vallerand and Miquelon (2007) suggest that passion is one key determinant of experts' involvement in their activity, and to engage in the activity for long hours, one must love what they do and have the desire to pursue engagement, especially when times are rough.

Vallerand et al. (2006, Study 2) examined the DMP among a sample of high school basketball players. The authors found that both harmonious and obsessive passion led to engagement in deliberate practice (i.e., participating in the activity with clear goals of improving on certain task components), which led to objective performance (i.e., coaches rating of the athlete's performance). Moreover, Vallerand et al. (2006, Study 1) stated that athletes with harmonious passion toward sport were more likely to experience positive affective experiences in their sport than athletes with an obsessive passion among samples of collegiate recreational athletes. In another study with water-polo and synchronized swimmers Vallerand and colleagues (2006, Study 3 ) found that harmonious passion was positively associated with the achievement of performance-related goals and subjective well-being. Obsessive passion, on the other hand, was positively associated with achievement of performance-related goals, but unrelated with subjective well-being.

Aggression. Aggression in sport is well researched topic. According to some researchers, aggression is one of the most important problems in sports today (Gee \& Potwarka, 2014; Sacks, Petscher, Stanley, \& Tenenbaum, 2003). Donahue, Rip, and Vallerand (2009) indicate to the best of their knowledge that the relationship between aggression and passion has not been empirically studied among passionate players. Therefore, the purpose of their study(s) was to examine the interplay 
between harmonious and obsessive passion and aggressive behavior in sport. Using the DMP as a guiding framework, high school basketball players indicated their level of passion and aggression during typical basketball situations using self-reported questionnaires. In the first study, results demonstrated that athletes with an obsessive passion for basketball reported higher levels of aggression than athletes with a harmonious passion. In the second study harmonious-passionate and obsessive-passionate participants were randomly assigned to two conditions, a self-threat and a self-affirmation condition. Results indicated that obsessively-passionate players reported higher levels of aggression than harmonious-passionate players in the self-threat condition, while no differences emerged between the two passionate groups for the self-affirmation condition. The authors concluded that obsessive passion is associated with aggressive behavior, especially when there is a threat to the person's identity. Moreover, the love for one's sport may lead to maladaptive interpersonal behavior, especially if such love is entrenched in a sense of identity that is contingent on doing well in their particular sport (Donahue, Rip, \& Vallerand, 2009).

To our knowledge, passion has not been explored in relation to the outcome variable of attitudes toward PEDs. More specifically, obsessive and harmonious passions have not been explored as predictors of attitudes toward PEDs in intercollegiate or recreational sport settings.

\section{Attitudes Toward Performance Enhancing Drugs}

PEDs have been a contentious issue in competitive sport for decades (Petróczi \& Aidman, 2009). The development of effective antidoping prevention requires a better understanding of the underlying mechanisms that may render some athletes more vulnerable to doping than others, which may include attitudes toward PEDs (Petróczi \& Aidman, 2008).

Assessing athletes' attitudes toward prohibited performance-enhancing substances and doping in general has had a long history in sport psychology. In the past 35 years, athletes have been questioned about their beliefs about the positive outcomes of using performance-enhancing substances, providing researchers with a reasonably good perspective into individuals' doping behavior (Petróczi \& Aidman, 2009). Laure (1997) indicates that the motives for using performance-enhancing substances can be sorted into two main categories. The first category deals with physiological aspects, such as increasing strength, endurance, dealing with tiredness, injury and/or lack of training, while the second category deals with psycho-social elements, such as achieving external goods, societal expectations, pressure to win, and personal desire to be acknowledged.

Beyond the scope of sports performance, improving appearance is also another reason for using drugs (Melia, Pipe, \& Greenberg, 1996; Williamson, 1993). Many athletes see doping as a necessary mean to an end (Curry \& Wagman, 1999) and do not consider using drugs as cheating. Laure and Reinsberger (1995) indicate that this might be the case as athletes do not take the drugs to replace hard work and training, but to add the extra edge to the work they have already done to increase the probability of winning and having something valuable in return.

Backhouse, Atkin, McKenna \& Robinson (2007) have indicated that current research methodologies used to examine athletes and their support networks' 
attitudes to doping in sport is weak. For the majority of the existing measurement tools, the scales development processes have not been reported and the scales used were not subjected to psychometric testing, which seriously undermines the validity and reliability of any inference made based on the scores obtained from those scales. Therefore, to rectify this issue Petróczi (2002) and Petróczi and Aidman (2009) have suggested the Performance Enhancement Attitude Scale (PEAS) to measure general attitudes toward doping in athletes and have concluded that the PEAS is a useful and sound tool for measuring self-declared attitudes toward doping.

Since the development of the PEAS, it has been used in studies exploring a doping behavioral model (Petróczi, 2002) and social desirability effect (Petróczi \& Nepusz, 2006); comparing implicit or explicit attitudes toward doping (Petróczi, Aidman, \& Nepusz, 2008); and investigating doping-related false consensus effects (Petróczi, Naughton, Nepusz, Backhouse, \& Mazanov, 2008). In addition, Morente-Sánchez, Femia-Marzo, and Zabala (2014) reported a significant negative relationship between PEAS and self-efficacy, and weak but significant negative correlation with self-esteem.

Petróczi and Aidman's (2009) review of the psychometric properties of PEAS concluded that the measure possesses good reliability $(\alpha=.71$ to .91 , test-retest $r>$ $.75)$ and acceptable validity estimates. More recent literature has revealed similar findings (c.f., Brand, Heck, and Ziegler, 2014). Morente-Sánchez et al.'s. (2014) Spanish version of the PEAS reported satisfactory psychometric properties. More specifically, internal consistency ( $\alpha=.71$ to .85 ) and test-retest reliability were sound, while acceptable measurement model fit suggested sufficient evidence to sustain the construct validity of the scale.

\section{Method}

\section{Sample and Data Collection Procedure}

Respondents were 587 male and female collegiate varsity $(N=348)$ and recreational coed $(N=239)$ sport participants engaged in one of several sports (e.g., ice hockey, basketball, volleyball, football, rugby, soccer, field hockey). There was no possibility for sport overlap when collecting data (i.e., varsity athletes that might participate in recreational sports). University athletes were selected as the target population for two reasons. First, issues related to PEDs in collegiate sport are often cited as a growing concern among athletic administrators. Moreover, to address the previously stated research questions, the collegiate sporting environment provides an ideal context to make meaningful comparisons between elite and recreational athletes, competitive levels and sex.

Athletic Departments and coaches at four southern Ontario universities were contacted and asked for permission to survey varsity athletes and recreational participants. Once permission was granted, dates and times were arranged with varsity teams and recreational groups to complete the questionnaire. Varsity athletes completed the questionnaire onsite in the team's locker room after practice, while recreational participants completed the questionnaire before or after a scheduled recreational game at the playing venue. Recreational teams that were sought for data collection competed in the advanced or all-star levels of their campus recreation 
programs. The questionnaire assessed varsity and recreational athletes' passion for competitive sports as it pertained to their particular activity of engagement, as well as their attitude toward PEDs in sport. These measures are described in the following section. The questionnaire also asked respondents to provide background information including their age, sex, competitive level (i.e., varsity or recreational), years played at current level of competition, and total number of years they participated in the sport being played at the time of data collection.

\section{Measures of Passion \& Attitude Toward Performance Enhancing Drugs}

The Passion Scale (Vallerand et al., 2003). The passion scale consists of two subscales, Obsessive and Harmonious passion of six items each, and were measured on a 7-point Likert scale, from 1= not agree at all, 7= very strongly agree. For the purpose of this study the items were modified to ask about competitive sport. An example of an obsessive item was "I have almost an obsessive feeling about competitive sports," and an example of a harmonious item was "Competitive sport allows me to live a variety of experiences." The Passion scale has been used in several studies and has been found to display high levels of validity and reliability (Vallerand et al., 2006). Internal consistency for obsessive and harmonious passion scale dimensions were deemed acceptable (Cronbach's alphas equaled .83 and .86 respectively). Results from a confirmatory factor analyses (CFA) conducted in the current study confirmed a two-factor structure of the Passion Scale $\chi^{2}(d f=53, n=$ $587)=473.03, p<.001 ; \mathrm{CFI}=.86, \mathrm{RMESA}=.11, \mathrm{CMIN} / \mathrm{DF}=8.92$. Table 1 presents the items used to measure harmonious and obsessive passion. Higher scores on the obsessive passion dimension imply rigid persistence with an activity, to the extent that participation in competitive sport may be an uncontrollable force in one's life (i.e., participation takes priority over other aspects of people's lives). Higher scores on the harmonious passion dimension imply participation in competitive sport may represent a more balanced aspect of people's lives.

Performance Enhancement Attitude Scale (PEAS: Petróczi, 2006). The PEAS is a 17-item inventory which measures "general" doping attitudes. Doping attitude is defined as an individual's predisposition toward PEDs and methods (Petróczi, 2007). PEDs (i.e., doping) were defined to participants as any substance or method that is taken to perform better athletically and that is prohibited by a relevant sport governing body (e.g., WADA; Canadian Interuniversity Sport; Ontario University Athletics). The PEAS is measured on a 7-point Likert scale from 1= strongly disagree to 7= strongly agree. Example items are "doping is necessary to be competitive," and "doping is not cheating since everyone is doing it." No neutral response is offered and all 17 items are scored in the same direction. The PEAS total score ranges from 17 to 119 , with higher scores denoting positive or permissive attitudes to doping and lower scores display negative or intolerant attitudes toward doping (Petróczi, 2006). Internal consistency for the PEAS was .89. Table 2 presents the items used to measure attitudes toward PEDs. Although an assumption is made that PEAS is assessed with reference to people's sport of interest, respondents attitudes 


\section{Table 1 Items Used to Measure Harmonious and Obsessive Passion}

\begin{tabular}{ll}
\hline Passion Scale & Items \\
\hline Obsessive Passion & "I have difficulty controlling my urge to play competitive sports" \\
& "I have almost an obsessive feeling about playing competitive sport" \\
& "Competitive sport is the only thing that really turns me on" \\
& "If I could, I would only participate in competitive sport" \\
& "Competitive sport is so exciting that I sometimes lose control over it" \\
& "I have the impression that competitive sport controls me" \\
"Competitive sport is in harmony with the other activities in my life" & "The new things that I discover with competitive sport allow me to \\
appreciate it even more" & "Competitive sport reflects the qualities I like about myself" \\
& "Competitive sport allows me to live a variety of experiences" \\
& "Competitive sport is well integrated in my life" \\
& "Competitive sport is in harmony with other things that are part of me"
\end{tabular}

Note: All items were assessed on a 7-point Likert scale from strongly disagree to strongly agree

toward PEDs are assessed in relation to sports in general. Thus, responses to the PEAS reflect a more global perspective regarding PED attitudes.

\section{Results}

The average age of the participants was 20.97 years $(S D=2.66)$. The sample was $63.70 \%$ male and $36.30 \%$ female, while $59.20 \%$ competed at the varsity level and $40.80 \%$ competed at the recreational level. Participants competed at their current level of competition for an average of 3.20 years $(S D=3.01)$ and had participated in their sport for an overall average of 11.56 years $(S D=5.17)$.

Descriptively, the average for obsessive passion was $3.83(S D=1.27)$, while the average for harmonious passion was $5.47(S D=.96)$. In addition, the average for attitudes toward PEDs was $39.62(S D=14.53)$. The results indicated a sex difference for attitudes toward PEDs, with men $(M=43.08, S D=15.36)$ reporting a higher score than women $(M=33.49, S D=10.43), t(582)=8.06, p<.001$. This finding is consistent with previous research (Singhammer, 2012). There were no overall sex differences for obsessive or harmonious passion.

Our results revealed three group differences with the core measures and competitive level. Varsity athletes $(M=4.04, S D=1.18)$ reported higher levels of obsessive passion than recreational athletes $(M=3.53, S D=1.32), t(580)=4.83$, $p<.001$. Varsity athletes $(M=5.67, S D=.79)$ also reported higher levels of harmonious passion than recreational athletes $(M=5.19, S D=1.10), t(581)=6.10$, $p<.001$. On average recreation participants indicated more permissive attitudes 


\section{Table 2 Items Used to Measure Attitudes of Performance Enhancing Drugs}

\begin{tabular}{l}
\hline PEAS Items \\
\hline "Only the quality of performance should matter, not the way athletes achieve it" \\
"Athletes have no alternative career choices but sport" \\
"The media blows the doping issue out of proportion" \\
"Athletes often lose time due to injuries and drugs can be used to help make up the lost \\
time" \\
"Athletes in my sport are pressured to take performance enhancing drugs" \\
"Athletes who take recreational drugs use them because they help them in sport \\
situations" \\
"Athletes should not feel guilty about breaking the rules and taking performance \\
enhancing drugs" \\
"The risks related to doping are exaggerated" \\
"Doping is necessary to be competitive" \\
"Recreational drugs assist in motivating athletes to train and compete at the highest \\
level" \\
"Doping is an unavoidable part of competitive sports" \\
"Recreational drugs help to overcome boredom outside of competition" \\
"There is no difference between drugs and the technical equipment that can be used to \\
enhance performance" \\
"The media should talk less about doping" \\
"Doping is not cheating because everyone is doing it" \\
"Health problems related to rigorous training and injuries are just as bad as doping side \\
effects" \\
"Legalizing performance enhancements would be beneficial for sports"
\end{tabular}

Note: All items were assessed on a 7-point Likert scale from strongly disagree to strongly agree

of PEDs $(M=44.04, S D=36.56)$ than varsity participations $(M=36.56, S D=$ $12.43), t(582)=-6.32, p<.001$.

\section{Passion as a Predictor of PEAS (Full Sample)}

The results for the regression analysis exploring associations between passion and attitudes toward PEDs are displayed in Table 3. After controlling for age, sex, years played at current level, total years playing that sport, and current level of competition, obsessive and harmonious passion (Model 2) accounted for $21 \%$ of the variance in athletes' attitudes toward PEDs $\left(F=21.23, p<.001, R^{2}=.21\right)$. Higher 


\section{Table 3 Association of Passion and PEAS Full Sample}

\begin{tabular}{lccccc}
\hline \multirow{2}{*}{ Variables } & \multicolumn{2}{c}{ Model 1 } & & \multicolumn{2}{c}{ Model 2 } \\
\cline { 2 - 3 } \cline { 5 - 6 } Constant & $\boldsymbol{B}$ & SE & & $\boldsymbol{B}$ & SE \\
Age & $42.06^{* *}$ & 5.50 & & $53.42^{* *}$ & 6.16 \\
Sex & -.05 & .28 & & -.02 & .27 \\
Years Played at Current Level & $.26^{* *}$ & 1.23 & & $.24^{* *}$ & 1.23 \\
Total Years Playing Sport & .02 & .24 & & .01 & .23 \\
Current Level of Competition & .01 & .12 & & -.01 & .12 \\
Obsessive Passion & $-.17^{* *}$ & 1.32 & & $-.15^{* *}$ & 1.30 \\
Harmonious Passion & & & & $.26^{* *}$ & .48 \\
$\mathrm{R}^{2}$ & & & & $-.29^{* *}$ & .65 \\
\hline
\end{tabular}

$N=556, * p<.05, * * p<.001$

scores on obsessive passion items were associated with more permissive attitudes toward PEDs $(B=.26, p<.001)$. Higher scores on harmonious passion items were associated with less permissive attitudes toward PEDs $(B=-.29, p<.001)$.

\section{Passion Predictor of PEAS in Co-Ed Recreational Collegiate Sporting Environments}

The results for the regression analysis exploring associations between passion and attitudes toward PEDs for recreational participants can be found in Table 4. F (5, $223)=2.68, p<.05$. After controlling for age, sex, years played at current level, total years playing that sport, and current level of competition, obsessive and harmonious passion (Model 2) accounted for $17 \%$ of the variance in athletes' attitudes toward PEDs $\left(F=7.25, p<.001, R^{2}=.17\right)$. Higher scores on obsessive passion items were associated with more permissive attitudes toward PEDs $(B=.33, p<.001)$. Higher scores on harmonious passion items were associated with less permissive attitudes toward PEDs $(B=-.36, p<.001)$.

\section{Passion as Predictor of PEAS in Varsity Collegiate Sporting Environments}

The results for the regression analysis exploring associations between passion and attitudes toward PEDs for varsity participants can be found in Table 5. After controlling for age, sex, years played at current level, and total years playing that 
Table 4 Association of Passion and PEAS for Co-Ed Recreational Sports

\begin{tabular}{lcrrrrr}
\hline & \multicolumn{2}{c}{ Model 1 } & & \multicolumn{2}{c}{ Model 2 } \\
\cline { 2 - 3 } \cline { 6 - 7 } Variables & $\boldsymbol{B}$ & SE & & B & \multicolumn{1}{c}{ SE } \\
\hline Constant & $49.18^{* *}$ & 9.79 & & $57.64^{* *}$ & 10.25 \\
Age & -.05 & .39 & & .01 & .37 \\
Sex & $.19 *$ & 3.12 & & $.17^{*}$ & 3.01 \\
Years Played at Current Level & .08 & .35 & & .06 & .33 \\
Total Years Playing Sport & -.10 & .25 & & -.10 & .24 \\
Obsessive Passion & & & & $.33^{* *}$ & .86 \\
Harmonious Passion & & & & $-.36^{* *}$ & 1.04 \\
$\mathrm{R}^{2}$ & & & & .17 & - \\
\hline
\end{tabular}

$N=223, * p<.05, * * p<.001$

Table 5 Association of Passion and PEAS for Varsity Sports

\begin{tabular}{lrrrrrr}
\hline & \multicolumn{2}{c}{ Model 1 } & & \multicolumn{2}{c}{ Model 2 } \\
\cline { 2 - 3 } \cline { 6 - 7 } Variables & $\boldsymbol{B}$ & SE & & B & SE \\
\hline Constant & $37.68^{* *}$ & 9.77 & & $51.64^{* *}$ & 10.65 \\
Age & -.06 & .59 & & -.07 & .57 \\
Sex & $.31^{* *}$ & 1.35 & & $.30^{* *}$ & 1.31 \\
Years Played at Current Level & -.01 & .65 & & -.01 & .63 \\
Total Years Playing Sport & .10 & .22 & & .09 & .30 \\
Obsessive Passion & & & & $.20^{* *}$ & .56 \\
Harmonious Passion & & & & $-.25^{* *}$ & .85 \\
$\mathrm{R}^{2}$ & & & & .15 & - \\
\hline
\end{tabular}

$N=332, * p<.05, * * p<.001$

sport, obsessive and harmonious passion (Model 2) accounted for $15 \%$ of the variance in athletes' attitudes toward PEDs $\left(F=8.21, p<.001, R^{2}=.15\right)$. Higher scores on obsessive passion items were associated with more permissive attitudes toward PEDs $(B=.20, p<.001)$. Higher scores on harmonious passion items were associated with less permissive attitudes toward PEDs $(B=-.25, p<.001)$. 


\section{Passion as a Predictor of PEAS by Competitive Level and Sex for Varsity Athletes}

Male Varsity Athletes. The results for the regression analysis exploring the associations between passion and attitudes toward PEDs for male varsity participants can be found in Table 6. After controlling for age, years played at current level, and total years playing that sport, obsessive and harmonious passion (Model 2) accounted for $12 \%$ of the variance in athletes' attitudes toward PEDs $(F=4.29$, $p<.05, R^{2}=.12$ ). Higher scores on obsessive passion items were associated with more permissive attitudes toward PEDs $(B=.24, p<.05)$. Higher scores on harmonious passion items were associated with less permissive attitudes toward the use of PEDs $(B=-.40, p<.001)$.

\section{Table 6 Association of Passion and PEAS for Male Varsity Athletes}

\begin{tabular}{lcrrrrr}
\hline & \multicolumn{2}{c}{ Model 1 } & & \multicolumn{2}{c}{ Model 2 } \\
\cline { 2 - 3 } \cline { 5 - 6 } Variables & \multicolumn{1}{c}{$\boldsymbol{B}$} & SE & & B & SE \\
\hline Constant & $44.01^{*}$ & 17.54 & & $68.26^{* *}$ & 18.23 \\
Age & -.02 & 1.04 & & -.02 & .98 \\
Years Played at Current Level & -.06 & 1.07 & & -.07 & 1.02 \\
Total Years Playing Sport & .02 & .29 & & -.02 & .27 \\
Obsessive Passion & & & & $.24^{*}$ & .93 \\
Harmonious Passion & & & & $-.40^{* *}$ & 1.36 \\
$\mathrm{R}^{2}$ & & & & .12 & - \\
\hline
\end{tabular}

$N=161, * p<.05, * * p<.001$

Table 7 Association of Passion and PEAS for Female Varsity Athletes

\begin{tabular}{lrrrrrr}
\hline & \multicolumn{2}{c}{ Model 1 } & & \multicolumn{2}{c}{ Model 2 } \\
\cline { 2 - 3 } \cline { 6 - 7 } Variables & $\boldsymbol{B}$ & SE & & B & SE \\
\hline Constant & $36.73^{*}$ & 12.56 & & $41.83^{*}$ & 13.72 \\
Age & -.05 & .71 & & -.07 & .71 \\
Years Played at Current Level & .05 & .84 & .07 & .83 \\
Total Years Playing Sport & .07 & .21 & .03 & .21 \\
Obsessive Passion & & & & $.20^{*}$ & .69 \\
Harmonious Passion & & & & -.12 & 1.04 \\
$\mathrm{R}^{2}$ & & & & .04 & - \\
\hline
\end{tabular}

$N=170,{ }^{*} p<.05, * * p<.001$ 
Female Varsity Athletes. The results for the regression analysis exploring the associations of passion and attitudes toward PEDs for female varsity participants can be found in Table 7. After controlling for age, years played at current level, and total years playing that sport, obsessive and harmonious passion (Model 2) accounted for $4 \%$ of the variance in athletes' attitudes toward PEDs $(F=1.52$, $\left.p<.05, R^{2}=.04\right)$. Higher scores on obsessive passion items were associated with more permissive attitudes toward PEDs $(B=.20, p<.05)$, while the association between attitudes toward PEDs and harmonious passion was not significant $(B=$ $-.12, p=-.15)$.

\section{Discussion}

\section{Summary and Discussion of Results}

Sample scores from PEAS were low, which suggests that respondents held relatively conservative attitudes toward PEDs. Passion emerged as a significant predictor of attitude toward PEDs when considering the full sample of athletes (i.e., RQ 1), coed recreational athletes (RQ 2), and male and female varsity athletes (RQ 3 and RQ 4). In particular, results of the study revealed that in all study, contexts (i.e., coed recreational, varsity and varsity sex split) obsessive passion emerged as a significant positive predictor of attitudes toward PEDs. In other words, when controlling for sex and competitive level (recreational or varsity), athletes with stronger obsessive passion for their sport of interest were more likely to hold a favorable (i.e., more permissive) attitude toward PEDs. Conversely, harmonious passion emerged as a significant negative predictor of attitude toward PEDs except for the female varsity athlete group. Male varsity athletes, and male and female recreational athletes with stronger harmonious passion for their sport of interest were more likely to hold a less favorable (i.e., more conservative) attitude toward PEDs. It was interesting to observe that harmonious passion did not emerge as a significant negative predictor of attitudes toward PEDs among female varsity athletes. That said, the relationship between these two variables was negative and approaching statistical significance.

These results suggest when participating in a sporting activity becomes internally controlling, as opposed to an integrative and balanced self-process, the possibility for more permissive attitudes toward PEDs can occur. In particular, when their own participation becomes overly contingent on self-esteem and identity, athletes may hold more permissive attitudes toward illegal and banned substances (i.e., PEDs). The notion that obsessively passionate athletes are more likely to hold permissive attitudes toward PEDs might be understood in relation to an "overconformance" to the norms of the sport ethic. Hughes and Coakley (1991) refer to the sport ethic as a set of norms accepted as the dominant standards for defining what it means to be accepted as an athlete in sports, inside those specific social worlds. Specifically, their notion of the sport ethic follows four basic norms, which include: 1) Athletes are dedicated to "the game" above all other thing, 2) An athlete strives for distinction, 3) An athlete accepts risks and plays through pain, and 4) An athlete does not accept any obstacles in the pursuit of possibilities (Hughes \& Coakley, 1991). If obsessively passionate athletes internalize such principles, they may be more likely to adopt lenient stances on PEDs. 
Our results also suggest that athletes who perceived their sport to be a more "harmonious" addition to their lives held more negative or conservative attitudes toward PEDs. Vallerand (2010) states that when harmonious passion is the focus, individuals do not experience uncontrollable urges to engage in the passionate activity, but rather, these individuals freely choose to engage in the activity on their own terms. As a result, more harmonious sport orientations may foster more positive feelings and enjoyment both during and after participating in the activity (Vallerand, 2010). It would seem that athletes are more likely to derive enjoyment from experiences they are harmoniously passionate about. These individuals may be less likely to hold permissive attitudes toward PEDs, perhaps because they perceive their participation in as a more welcomed and balanced addition to their life, instead of a more dominant part of their life.

Overall, our results show that as obsessive passion rises, PEAS rises, and as harmonious passion rises, PEAS falls. Yet, it was interesting to observe that varsity athletes had higher harmonious passion scores than recreational athletes, and also more favorable attitudes toward PEDs. Although all harmonious items are summed to for an overall measure, one particular item might be useful in helping explain this rather curious finding. Specifically, varsity athletes $(M=6.12, S D=.87)$ reported significantly higher scores than recreation athletes $(M=5.43, S D=1.30), t(582)=$ $7.05, p<.001$ on the harmonious item of: "Competitive sport allows me to live a variety of experiences", which might be driving much of the differences we observed in the composite metric. Respondents, for example, may have interpreted this item to mean a variety of experiences connected to the sport they play. If this was the case, is reasonable to argue that participation on a varsity athletic team would offer a more extensive array of experiences than participation on a recreational team, especially as it relates to opportunities to travel with teammates, attend special events, as well as more thorough training and practice regiments.

In summary, our findings reveal important insights about relationships between passion and attitudes toward PEDs. By doing so, our paper contributes to a growing body of literature aimed at identifying at-risk athletes and indicators of more lenient attitudes toward PEDs including transition phases in sporting career such as moving from amateur to professional (Lentillon-Kaestner \& Carstairs, 2011), periods of instability in an elite career such as selection or de-selection to a team (Mazanov, Huybers, \& Connor, 2011), or if an athlete fears the risk of failure as a result of declining performance (Bette, 2004).

\section{Implications for Practice}

Our findings have implications for competitive sport coaches and administrators. We suggest programing efforts be built on principles of fun and enjoyment. Losing sight of these principles might create conditions that foster obsessive passion. We are not suggesting that winning and success be de-emphasized, for the sake of fun and enjoyment. Based on our findings, we advocate for collegiate athletic experiences that reinforce to student-athletes the importance of deriving fun and enjoyment from participation. Moreover, coaches and administrators should be mindful of the central role such activities can have in lives of athletes. Coaches and administrators should create cultures that allow athletes to engage in social worlds that extend beyond the particular activity. 
Specifically, coaches and administrators can encourage athletes to continually reflect on their experiences and what sport means in their lives. Coaches and athletic administrators should create environments where athletes are able to speak openly should they begin to feel disconnected from what might be important in their lives. This open discourse might help identify athletes who might be at risk for becoming too obsessive about sport. In addition to winning, the goal should be the development of well-balanced student-athletes who effectively integrate sport into their lives and identities.

While it is important for coaches and administrators to promote well balanced growth in their athletes, we must also keep in mind contextual forces that might inhibit the promotion of these ideals. Most collegiate programs are run as businesses in which winning and success are primary aims. Winning and success are often privileged over fun and enjoyment outcomes in many Canadian collegiate competitive sport contexts. With an emphasis on winning, competitive cultures may adopt 'win at all costs' mentalities, which may impact athletes' attitudes toward PEDs. We acknowledge that winning and success are important outcomes, but the wellbeing and development of student-athletes should be the main concern of coaches and administrators.

\section{Limitations and Future Research}

This study is not without limitations. However, at the same time these limitations offer opportunities for future research. This study did not delineate by sport. For instance, we did not examine the specific sports that the athletes participated in (e.g., football, ice-hockey, soccer, volleyball). The analyses were conducted using all sports and participants. Future research could explore how each type of sport might influence passion and attitudes toward PEDs. Power and performance sports, for example, might illicit different results compared with more graceful and artistic, or noncontact sports.

Another limitation to note for the current study was the absence of assessing actual behavior. Our study only explored associations between passion and the attitudes toward PEDs. It has been noted that there is great difficulty when researching doping behaviors of athletes, as there is a struggle to actually source participants who actually dope and use banned substances (Boardley \& Kavussanu, 2011). Future research could perhaps use an experimental design and provide conditions to examine actual behavior with respect to doping and banned substance use.

Moreover, we employed a cross sectional research design. Our results only provide a snap-shot of the associations explored. Future research would benefit from more longitudinal designs, as passion and attitude toward PEDs can potentially change and evolve over time. The particular attitude and perceived passion athletes hold now while engaged in their sport could change as they move through their university careers and into life after school. In addition, this study only explored relationships of passion and attitudes toward PEDs on Southern Ontario. It would be interesting for future research to explore these relationships in other geographical areas such as the United States and Europe, as well as utilizing noncollegiate sporting contexts (e.g., high-school levels, professional levels, amateur levels). 
Although the relationship between harmonious passion and attitude toward PEDs was negative among female varsity athletes, we are unsure as to why this association was not statistically significant. Indeed, sex differences with respect to associations between harmonious passion and attitude toward PEDs requires further exploration.

Lastly, we acknowledge that PEDs were not assessed in reference to participants own sport of interest as a limitation to this study. However, our study was exploratory in nature, particularly as it relates to the relationships between passion and attitudes toward PEDs. Therefore, future research should carefully consider the sport context when assessing relationships between passion and attitudes toward PEDs.

\section{Conclusion}

Our study revealed strong and similar association between passion and attitude toward PEDs among samples of both recreational and varsity athletes. Regardless of competitive level (coed recreational or varsity) or sex (male or female varsity athletes) obsessive passion remained a strong positive predictor of attitudes toward PEDs. Harmonious passion, on the other hand, emerged as a significant negative predictor of attitude toward PEDs in all study contexts expect among female varsity athletes. However, the negative direction of this relationship was consistent with the other sample contexts. Finally, the amount of variance in athletes' attitude toward PEDs explained by obsessive and harmonious passion ranged from $4 \%$ to $21 \%$ in all study contexts. Thus, while passion is an important factor in shaping athletes attitudes toward PEDs, there are several other factors (which we did not explore) that might shape and predict such attitudes.

\section{References}

Baron, D.A., Martin, D.M., \& Magd, S.A. (2007). Doping in sports and its spread to at-risk populations: An international review. World Psychiatry; Official Journal of the World Psychiatric Association (WPA), 6, 54-59. PubMed

Backhouse, S.H., Atkin, A., McKenna, J., \& Robinson, S. (2007). International literature review: Attitudes, behaviours, knowledge and education-drugs in sport: Past, present and future. Report to the World Anti-Doping Agency (WADA). Retrieved from http:// www.wada-ama.org/en/dynamic.ch?pageCategory.id=513

Bette, K.H. (2004). Biographical risks and doping. In J. Hoberman \& V. Møller (Eds.), Doping and Public Policy. Odense: University of Southern Denmark.

Boardley, I.D., \& Kavussanu, M. (2011). Moral disengagement in sport. International Review of Sport and Exercise Psychology, 1-16.

Brand, R., Heck, P., \& Ziegler, M. (2014). Illegal performance enhancing drugs and doping in sport: A picture-based brief implicit association test for measuring athletes' attitudes. Substance Abuse Treatment, Prevention, and Policy, 9, 7. PubMed doi:10.1186/1747597X-9-7

Buckman, J.F., Farris, S.G., \& Yusko, D.A. (2013). A national study of substance use behaviors among NCAA male athletes who use banned performance enhancing substances. Drug and Alcohol Dependence, 131, 50-55. PubMed doi:10.1016/j.drugalcdep.2013.04.023 
Calfee, R., \& Fadale, P. (2006). Popular ergogenic drugs and supplements in young athletes. Pediatrics, 117, 577-589. PubMed doi:10.1542/peds.2005-1429

Crocker, J. (2002). Contingencies of self-worth: Implications for self-regulation and psychological vulnerability. Self and Identity, 1, 143-149. doi:10.1080/152988602317319320

Curry, L.A., \& Wagman, D.F. (1999). Qualitative description of the prevalence and use of anabolic androgenic steroids by United States power lifters. Perceptual and Motor Skills, 88, 224-233. PubMed doi:10.2466/pms.1999.88.1.224

Deci, E.L., \& Ryan, R.M. (2000). The "what" and "why" of goal pursuits: Human needs and the self-determination of behavior. Psychological Inquiry, 11, 227-268. doi:10.1207/ S15327965PLI1104_01

Donahue, E.G., Rip, B., \& Vallerand, R.J. (2009). When winning is everything: On passion, identity, and aggression in sport. Psychology of Sport and Exercise, 10, 526-534. doi:10.1016/j.psychsport.2009.02.002

Ericsson, K.A., \& Charness, N. (1994). Expert performance: Its structure and acquisition. The American Psychologist, 49, 71-76. doi:10.1037/0003-066X.49.8.725

Gee, C.J., \& Potwarka, L.R. (2014, in press). Controlling anger and aggression. In A. Papaioannou \& C. Hackfort (Ed.), Fundamental concepts in sport and exercise psychology: A worldwide view. Routledge.

Hagger, M.S., \& Chatzisarantis, N.L.D. (2005). Frist and higher order models of attitudes, normative influence, and perceived behavioural control in the theory of planned behaviour. British Journal of Social Psychology, 44, 513-535. PubMed doi:10.1348/014466604X16219

Hodgins, H.S., \& Knee, R. (2002). The integrating self and conscious experience. In E.L. Deci \& R.M. Ryan (Eds.), Handbook on self-determination research: Theoretical and applied issues (pp. 87-100). Rochester, NY: University of Rochester Press.

Hughes, R., \& Coakley, J. (1991). Positive deviance among athletes: The implications of overconformity to the sport ethic. Sociology of Sport Journal, 8(4), 307-325.

Irving, L.M., Wall, M., Neumark-Sztainer, D., \& Story, M. (2002). Steroid use among adolescents: Findings from project EAT. The Journal of Adolescent Health, 30, 243-252. PubMed doi:10.1016/S1054-139X(01)00414-1

Kernis, M.H. (2003). Toward a conceptualization of optimal self-esteem. Psychological Inquiry, 14, 1-26. doi:10.1207/S15327965PLI1401_01

Kindlundh, A.M., Isacson, D.G.L., Berglund, L., \& Nyberg, F. (1999). Factors associated with adolescent use of doping agents: Anabolic-androgenic steroids. Addiction (Abingdon, England), 94, 543-545. PubMed doi:10.1046/j.1360-0443.1999.9445439.x

Laure, P. (1997). Epidemiologic approach to doping in sport. Journal of Sports Medicine and Physical Fitness, 37, 218-224. PubMed

Laure, P., \& Reinsberger, H. (1995). Doping and high-level endurance walkers. Knowledge and representation of a prohibited practice. Journal of Sports Medicine and Physical Fitness, 35, 228-231. PubMed

Lentillon-Kaestner, V., \& Carstairs, C. (2010). Doping use among elite cyclists: A qualitative psychosociological approach. Scandinavian Journal of Medicine \& Science in Sports, 20, 336-345. PubMed doi:10.1111/j.1600-0838.2009.00885.x

Mazanov, J., Huybers, T., \& Connor, J. (2011). Qualitative evidence of a primary intervention point for elite athlete doping. Journal of Science and Medicine in Sport, 14, 106-110. PubMed doi:10.1016/j.jsams.2010.06.003

McDuff, D., \& Baron, D. (2005). Substance use in athletics: A sports psychiatry perspective. Clinics in Sports Medicine, 24, 885-897. PubMed doi:10.1016/j.csm.2005.06.004

Melia, P., Pipe, A., \& Greenberg, L. (1996). The use of anabolic-androgenic steroids by Canadian students. Clinical Journal of Sport Medicine, 6, 9-14. PubMed doi:10.1097/00042752-199601000-00004 
Morente-Sánchez, J., Femia-Marzo, P., \& Zabala, M. (2014). Cross-cultural adaptation and validation of the Spanish version of the performance enhancement attitude scale (Petróczi, 2002). Journal of Sports, Science, and Medicine, 13, 430-438. PubMed

National Center for Drug Free Sport. (2013). Drug free sport: Drug resources. Retrieved from: http://www.drugfreesport.com/drug-resources/performance-enhancing-drugssteroids.asp

National Collegiate Athletic Association (NCAA). (2008). NCAA banned-drugs classes 2008-2009. Retrieved March 25, 2014 from: http://www.ncaa.org/wps/wcm/connect/resources/file/eb178004a5bd0c0/banned\%20drugs\%2020080-09\%2006-02-08. pdf?MOD=AJPERES

Petróczi, A. (2002). Exploring the doping dilemma in elite sport: Can athlete's attitudes be responsible for doping? Published Doctor of Philosophy dissertation, University of Northern Colorado, USA.

Petróczi, A. (2006). Measuring attitude toward doping: Further evidence for the psychometric properties for the Performance Enhancement Attitude Scale. 14th Congress of the European Association of Sport Management. Nicosia, Cyprus. September 2006.

Petróczi, A. (2007). Attitudes and doping: A structural equation analysis of the relationship between athletes' attitudes, sport orientation and doping behaviour. Substance Abuse Treatment, Prevention, and Policy, 2, 34-47. PubMed doi:10.1186/1747-597X-2-34

Petróczi, A., \& Aidman, E.V. (2008). Psychological drivers in doping: The life-cycle model of performance enhancement. Substance Abuse Treatment, Prevention, and Policy, 3, 7. PubMed doi:10.1186/1747-597X-3-7

Petróczi, A., \& Aidman, E.V. (2009). Measuring explicit attitude toward doping: Review of Psychometric properties of the Performance Enhance Attitude Scale. Psychology of Sport and Exercise, 10, 390-396. doi:10.1016/j.psychsport.2008.11.001

Petróczi, A., Aidman, E.V., \& Nepusz, T. (2008). Capturing doping attitudes by self-report declarations and implicit assessment: A methodology study. Substance Abuse Treatment, Prevention, and Policy, 3, 9. PubMed doi:10.1186/1747-597X-3-9

Petróczi, A., Naughton, D.P., Nepusz, T., Backhouse, S., \& Mazanov, J. (2008). Comfort in big numbers: False consensus in hypothetical performance enhancing situations. Journal of Occupational Medicine and Toxicology (London, England), 3, 19. PubMed

Petróczi, A., \& Nepusz, T. (2006). The effect of self-impression management in social science doping research. Paper presented at the WADA International Conference on Ethics and Social Science Research on Anti-doping. Larnaca, Cyprus, April 2006.

Ryan, R.M., \& Deci, E.L. (2003). On assimilating identities to the self: A Self-Determination Theory perspective on internalization and integrity within cultures. In M.R. Leary \& J.P. Tangney (Eds.), Handbook of self and identity (pp. 253-272). New York, NY: Guilford.

Sacks, D.N., Petscher, Y., Stanley, C.T., \& Tenenbaum, G. (2003). Aggression and violence in sport: Moving beyond the debate. International Journal of Sport and Exercise Psychology, 1(2), 167-179. doi:10.1080/1612197X.2003.9671710

Singhammer, J. (2012). Age and gender specific variations in attitudes to performance enhancing drugs and methods. A cross-sectional study. Sport Science Review, 21, 5-6, 29-48.

Starkes, J.L., Deakin, J.M., Allard, F., Hodges, N.J., \& Hayes, A. (1996). Deliberate practice in sports: What is it anyway? In K.A. Ericsson (Ed.), The road to excellence: The acquisition of expert performance in the arts, sciences, sports, and games (pp. 81-106). Mahwah, NJ: Erlbaum.

Tricker, R. (2000). Painkilling drugs in collegiate athletics: Knowledge, attitudes, and use of student athletes. Journal of Drug Education, 30, 313-324. PubMed doi:10.2190/ N1K3-V8BK-90GH-TTHU

Vallerand, R.J. (2008). On the psychology of passion: In search of what makes people's lives most worth living. Canadian Psychology, 49, 1-13. doi:10.1037/0708-5591.49.1.1 
Vallerand, R.J. (2010). On passion for life activities: The dualistic model of passion. In M.P. Zanna (Ed.), Advances in experimental social psychology. New York, NY: Academic Press. doi:10.1016/S0065-2601(10)42003-1

Vallerand, R.J. (2012). The dualistic model of passion in sport and exercise. In G.C. Roberts \& D.C. Treasure (Eds.), Advances in motivation in sport and exercise (3rd ed., pp. 169-206). Champaign, IL: Human Kinetics.

Vallerand, R.J., Blanchard, C.M., Mageau, G.A., Koestner, R., Ratelle, C., Leonard, M., . . . Marsolais, J. (2003). Les passions de l'ame: On obsessive and harmonious passion. Journal of Personality and Social Psychology, 85, 756-767. PubMed doi:10.1037/00223514.85.4.756

Vallerand, R.J., \& Houlfort, N. (2003). Passion and work: Toward a new conceptualization. In D. Skarlicki \& D. Steiner (Eds.), Research in Social Issues in Management (Vol. 3, pp. 195-204). Greenwich, CT: Information Age.

Vallerand, R.J., \& Miquelon, P. (2007). Passion for sport in athletes. In D. Lavallee \& S. Jowett (Eds.), Social Psychology in Sport (pp. 249-262). Champaign, IL: Human Kinetics.

Vallerand, R.J., Rousseau, F.L., Grouzet, F.M.E., Dumais, A., Grenier, S., \& Blanchard, C.M. (2006). Passion in sport: A look at determinants and affective experiences. Journal of Sport \& Exercise Psychology, 28, 454-478.

WADA. (2014). The 2014 prohibited list: International standard. Retrieved June 26, 2014 from: http://www.wada-ama.org/Documents/World_Anti-Doping_Program/WADPProhibited-list/2014/WADA-prohibited-list-2014-EN.pdf

Williamson, D.J. (1993). Anabolic steroid use among students at a British college of technology. British Journal of Sports Medicine, 27, 200-201. PubMed doi:10.1136/ bjsm.27.3.200

Yusko, D.A., Buckman, J.F., White, H.R., \& Pandina, R.J. (2008). Alcohol, tobacco, illicit drugs, and performance enhancers: A comparison of use by college student athletes and non-athletes. Journal of American College Health, 57(3), 281-290. PubMed doi:10.3200/JACH.57.3.281-290 